\title{
Adipocytokines and Insulin Resistance
}

\section{The possible role of lipocalin-2, retinol binding protein-4, and adiponectin}

Eduardo EsteVe, MD, PHD

WiFREDO RICART, MD

José Manuel Fernández-Real, MD, PHD

I $\mathrm{t}$ is well known that adipocytes and resident macrophages that have migrated to adipose tissue produce and secrete a variety of biologically active mediators (adipocytokines), which are thought to contribute to the development of insulin resistance, type 2 diabetes, and cardiovascular disease (1).

The abnormal function of adipocytes may play an important role in the development of a chronic low-grade proinflammatory state associated with obesity (2). For example, adipocyte hypertrophy appears to lead to an imbalance between pro- and anti-inflammatory adipokines. The secretion of interleukin (IL)-6, IL-8, monocyte chemoattractant protein-1, and granulocyte colony-stimulating factor have been positively correlated with adipocyte size.

Adipose tissue is an important inflammatory source in obesity and type 2 diabetes, not only because of cytokines produced from the adipocyte itself, but also because of infiltration by proinflammatory macrophages (3). Not only do adipocytes, but also adipose tissue macrophage numbers, increase with obesity and participate in inflammatory pathways of obese individuals. Macrophages from adipose tissue are responsible for almost all adipose tissue tumor necrosis factor (TNF) $-\alpha$ and significant amounts of IL-6 production. Macrophages migrating to adipose tissue in response to high-fat feeding overexpress proinflammatory cytokines.

Different cytokines synthesized by adipocytes or by macrophages from adipose tissue may induce insulin resistance, such as IL-6, TNF- $\alpha$, leptin, resistin, adi- ponectin, retinol binding protein-4 (RBP4), or lipocalin-2 (LCN2). This review focuses on the latter adipocytokines, hinting at their role in obesity-associated insulin resistance.

LCN2 - LCN2 (or neutrophil gelatinase-associated lipocalin) is a recently identified adipokine that belongs to the superfamily of lipocalins (such as RBP4), which seems to affect glucose metabolism and insulin sensitivity (4). LCN2 protein has been implicated in diverse actions, such as apoptosis and innate immunity, and is expressed in several tissues, including neutrophils, liver, kidney, adipocytes, and macrophages (5).

Lipocalins comprise a class of proteins that are characterized by eight Bstrands that form a B-barrel defining a calyx. The calyx binds and transports a wide variety of molecules, such as retinol, fatty acids, and steroids, which are thought to define the biologic activity of the lipocalin.

LCN2 deficiency in mice resulted in an increased susceptibility to bacterial infection (6). Lipopolysaccharide and TNF- $\alpha$ are two of the strongest inducers of LCN2 production. Recently, the LCN2 gene was also identified as a novel IL-17induced gene (7).

LCN2 is highly expressed in adipose tissue in vivo and in vitro, and its secretion is regulated by the activation of inflammation and infection (4). LCN2 mRNA is also elevated in the liver of ob/ob mice, and circulating LCN2 levels are increased in obese animals and human subjects with type 2 diabetes $(5,8)$. In fact, expression of LCN2 is elevated by agents

From the Unit of Diabetes, Endocrinology and Nutrition, Biomedical Research Institute of Girona, and CIBEROBN Fisiopatología de la Obesidad y Nutrición, Girona, Spain.

Corresponding author: J.M. Fernández-Real,jmfernandezreal.girona.ics@gencat.cat.

The publication of this supplement was made possible in part by unrestricted educational grants from Eli Lilly, Ethicon Endo-Surgery, Generex Biotechnology, Hoffmann-La Roche, Johnson \& Johnson, LifeScan, Medtronic, MSD, Novo Nordisk, Pfizer, sanofi-aventis, and WorldWIDE.

DOI: $10.2337 / \mathrm{dc0} 0-\mathrm{S} 340$

(C) 2009 by the American Diabetes Association. Readers may use this article as long as the work is properly cited, the use is educational and not for profit, and the work is not altered. See http://creativecommons. org/licenses/by-nc-nd/3.0/ for details. that promote insulin resistance and is reduced by thiazolidinediones (8). In one study, serum concentrations of LCN2 were positively associated with waist circumference, percent body fat, systolic blood pressure, fasting glucose and insulin concentrations, fasting triglycerides, and markers for chronic inflammation. All these results persisted significantly after adjustment for sex and age (5). In another study, serum LCN2 levels were significantly elevated in patients with coronary heart disease and were independently associated with atherosclerosis (9).

Information on the dual effects of LCN2 on inflammation is sparse. The LCN2 promoter contains different binding sites for two proinflammatory transcription factors: nuclear factor kB (NF$\kappa \mathrm{B})$ and CCAAT/enhancer-binding protein (C/EBP) (7). Expression of LCN2 was elevated by agents that promote insulin resistance and was reduced by thiazolidinediones (8), partially explaining why activation of this gene in adipose tissue was associated with inflammation and obesity. Paradoxically, decreased LCN2 gene expression has no significant effect on lipid accumulation in adipocytes (8).

Conversely, LCN2 has recently been claimed to display anti-inflammatory effects, so that increased LCN2 levels in obesity and insulin resistance may constitute a protective mechanism against inflammation (10). Moreover, LCN2 upregulated peroxisome proliferatoractivated receptor (PPAR)- $\boldsymbol{\gamma}$ and its target genes, adiponectin, leptin, fatty acid synthase, and lipoprotein lipase in adipocytes. Concurrently, LCN2 antagonized TNF- $\alpha$ effects on adipocytes and macrophages: LCN2 protected adipocytes from TNF- $\alpha$-induced production of IL- 6 and monocyte chemoattractant protein-1 (MCP-1), attenuated TNF- $\alpha$ effect on glucose uptake, and completely reversed TNF- $\alpha$ inhibition of leptin and adiponectin secretion from adipocytes. The stimulatory effect of lipopolysaccharide on cytokine gene expression in macrophages was also significantly attenuated by LCN2 (10). Knocking down LCN2 expression resulted in decreased expression of PPAR- $\boldsymbol{\gamma}$. This suggests an anti-inflammatory effect of LCN2, via direct or indirect 


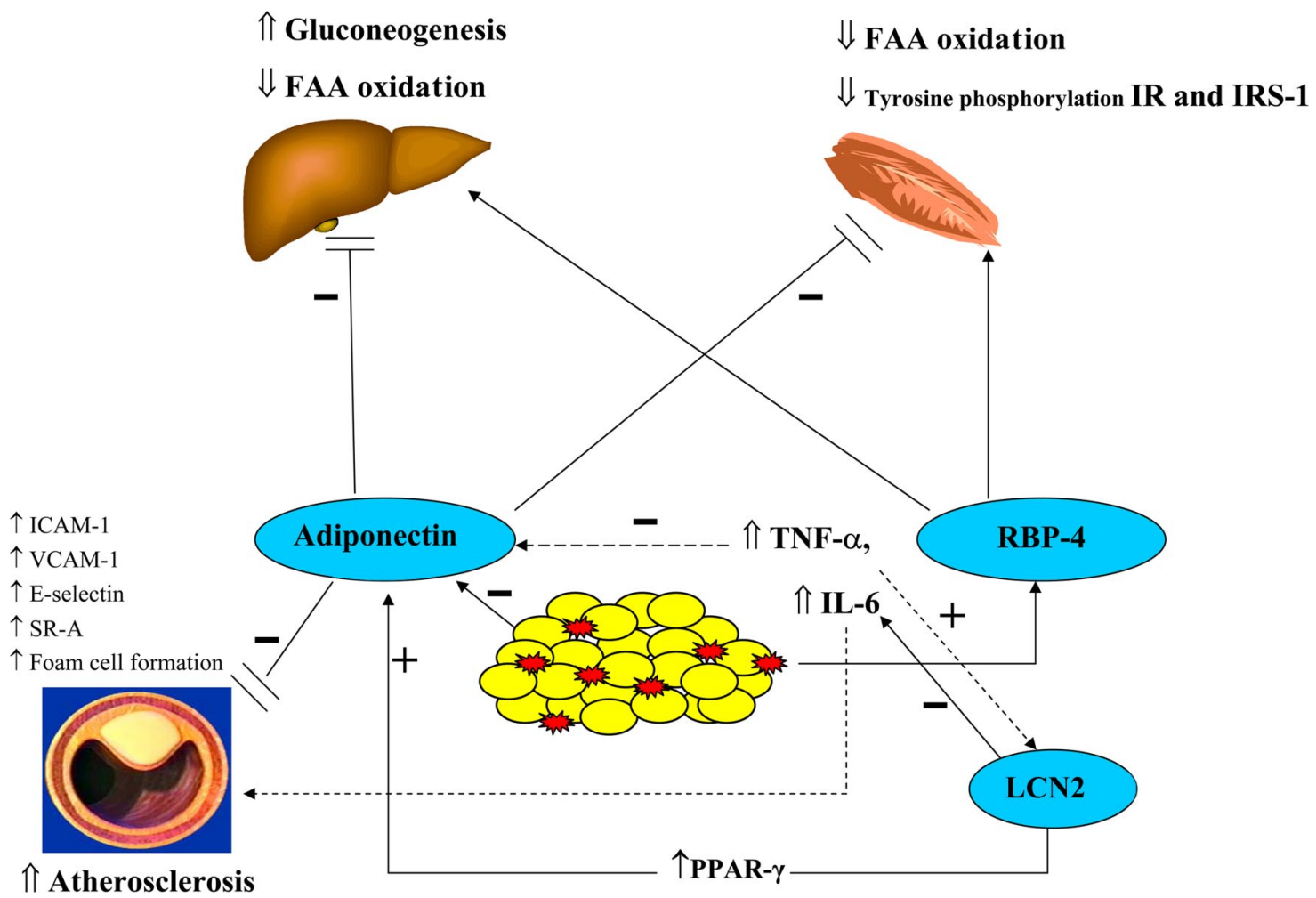

Figure 1-Brief summary of the adipocytokines discussed: increased adipose tissue mass is associated with decreased adiponectin levels and increased RBP4, IL-6, and TNF- $\alpha$ production, which in turn stimulates LCN2 synthesis. LCN2 upregulates adiponectin and downregulates TNF- $\alpha$. Decreased adiponectin and increased RBP4 levels are associated with decreased fatty acid oxidation, increased gluconeogenesis in the liver, and insulin resistance. FFA, free fatty acid; ICAM-1, intercellular adhesion molecule-1; IR, insulin receptor; IRS, insulin receptor substrate; PPAR, peroxisome proliferator-activated receptor; SR-A, scavenger receptor-A; VCAM-1, vascular cell adhesion molecule-1.

mechanisms, through the inhibition NFKB activity (10).

An additional mechanism that links LCN2 to inflammation is probably related to its structural characteristics, which allow the binding and transport of other molecules. LCN2 may take part in the host innate immune defense system. In fact, bacteriostatic effects are exerted by LCN2, and these effects are mediated through the binding of bacterial enterobactin siderophores to limit bacterial iron acquisition.

In conclusion, although LCN2 is directly linked to inflammation in association studies, the specific role of this molecule should be clarified. The increased levels of LCN2 during inflammation may reflect a protective role against inflammation.

RBP4 - RBP4 is a molecule found in the circulation, thought to be secreted mainly by adipose tissue and the liver (11). In the circulation, RBP4 is the principal transport protein for retinol (vitamin A) (11) and is encoded by the RBP4 gene, localized in the chromosome 10q23-q24 (12).
Increased serum RBP4 levels have been reported in subjects with obesity, insulin resistance, and type 2 diabetes (13) and in other insulin-resistant states, such as nonalcoholic fatty liver disease and the metabolic syndrome. Serum RBP4 concentration was negatively associated with insulin sensitivity measured by the clamp and was associated with type 2 diabetes development $(13,14)$. However, these associations were not found by other investigators $(15,16)$.

Circulating RBP4 concentration correlated positively with adiposity measures and with inflammatory parameters. Circulating RBP4 concentration was more associated with waist circumference and percent trunk fat than with percent body fat (17). The association between RBP4 and visceral fat was stronger than its association with BMI, indicating a greater role of visceral than subcutaneous fat in the relationship between RBP4 and insulin resistance. This finding was confirmed by other authors who described that visceral adipose tissue accumulation was the stronger predictor of RBP4 levels (18). In this sense, increased RBP4 mRNA expression in visceral, compared with subcuta- neous, adipose tissue has already been found (19). Circulating RBP4 levels also correlated positively with ectopic fat accumulation at hepatic and skeletal muscles (14).

The RBP4 genetic variations were also likely to affect measures of insulin resistance, BMI, waist-to-hip ratio, and circulating free fatty acids. Recent data indicated a role for RBP4 genetic variation in susceptibility to type 2 diabetes and insulin resistance, possibly through an effect on RBP4 expression. The RBP4 haplotypes were related to an increased risk of type 2 diabetes $(12,20)$. Diabetes risk RBP4 haplotype carriers had a higher mean visceral and subcutaneous RBP4 mRNA expression, compared with noncarriers (12). However, the associations among RBP4 levels, RBP4 gene expression, and measures of obesity or insulin resistance have not been universally described (15).

Several mechanisms link RBP4 to insulin resistance and type 2 diabetes. Transgenic expression of RBP4 in mice caused insulin resistance, whereas experimentally decreased RBP4 levels ameliorated insulin resistance. Other RBP4- 
associated effects were the increase of hepatic gluconeogenesis by enhancing the expression of phosphoenolpyruvate carboxykinase in the liver and the attenuated insulin signaling in skeletal muscle (11). Insulin signaling in primary human adipocytes was affected by RBP4 through blocking the insulin-stimulated phosphorylation of insulin receptor substrate- 1 at serine in position 307 (21). The level of GLUT4 protein in human adipocytes correlated positively with the rate of glucose disposal and inversely with the serum RBP4 level (13).

The link between RBP4 and type 2 diabetes could also be mediated through impaired insulin secretion. In one study, circulating RBP4 concentration was negatively associated with insulin secretion in humans. In fact, it is well known that retinol (the ligand for RBP4) is pathophysiologically linked to $\beta$-cell function. Retinol-binding protein circulates in serum, forming a complex with transthyretin, a transport protein for thyroxine. A recent investigation disclosed that transthyretin constitutes a functional component in pancreatic $\beta$-cell stimulussecretion coupling. The binding of RBP to the receptor is inhibited by transthyretin. Thus, it is possible that increased serum RBP4 prevents transthyretin from exerting its $\beta$-cell stimulus-secretion effects (16).

However, the mechanisms by which RBP4 induces insulin resistance are not well understood. Many adipokines have been found to be sexually dimorphic. Both leptin and adiponectin are increased in serum of women compared with men. This observation has been explained on the basis of different fat quantities and the influence of sex hormones. Plasma RBP4 concentrations, however, exhibit an opposite pattern. The median (range) for RBP4 in plasma was higher in men than in women (22). Plasma RBP4 levels in women over the age of 50 years were found to be significantly higher than those in women under the age of 50 years. No such age-associated difference in RBP4 plasma levels was observed in men (22). Thus, the pattern of RBP4 concentrations in serum resembles that of iron stores: higher in men than women, in whom iron stores increase after menopause.

An interaction between iron and vitamin A status, of which RBP4 is a surrogate, has long been recognized. For instance, vitamin A deficiency may impair iron metabolism and aggravate anemia, and iron deficiency anemia and vitamin A deficiency often coexist. Iron supplementation significantly increased plasma retinol and RBP (23).

In recent years, increased iron intake and raised iron stores have been recognized as significant independent contributors to insulin resistance. Interestingly, serum ferritin concentration was positively associated with serum RBP4 concentration in two independent samples (23). On multiple regression analyses to predict serum RBP4, log serum ferritin contributed significantly to RBP4 variance after controlling for BMI, age, and homeostasis model assessment value. Furthermore, serum RBP4 concentration decreased after iron depletion in type 2 diabetic patients. Finally, the iron donor, lactoferrin, led to increased dosedependent adipose tissue release of RBP4 (2.4-fold) and increased RBP4 expression, whereas apotransferrin and deferoxamine led to decreased RBP4 release (23).

Significant weight loss induced by diet, lifestyle interventions, bariatric surgery (gastric bypass), and gastric banding surgery led to decreased circulating RBP4 levels (24). The decrease in RBP4 in response to the intervention was closely associated to the decrease of inflammatory factors (C-reactive protein and IL-6). Nevertheless, smaller decreases in body weight after dietetic intervention did not induce the same effects on RBP4 levels.

Improved insulin resistance by exercise also reduced RBP4 levels and increased circulating adiponectin (13). Therefore, the insulin-sensitizing effects of exercise are associated with decreased RBP4.

In summary, there are reliable clinical and research studies suggesting the association of RBP4 with obesity and insulin resistance.

ADIPONECTIN - Adiponectin, believed to be produced almost exclusively by mature adipocytes, is the prototype of anti-inflammatory adipocytokines, decreased in obesity, and inversely correlated with insulin resistance, glucose intolerance, dyslipidemia, and atherosclerosis. Adiponectin receptors (AdipoR)- 1 and -2 are expressed in peripheral tissues and in the brain, where adiponectin mediates fatty acid metabolism and modulates energy homeostasis (25).

Adiponectin production is well known to be regulated by different cytokines. Adiponectin gene expression is known to be reduced by TNF- $\alpha$ and IL- 6 , whereas insulin sensitizers and PPAR- $\gamma$ agonists have been shown to increase adiponectin levels in mice and humans (25).

The negative relationship between adiponectin and adipose tissue is stronger with visceral fat rather than subcutaneous fat. For instance, obese adolescents with a high proportion of visceral fat and relatively low abdominal subcutaneous fat have decreased adiponectin and leptin levels independent of body weight (26). The reason why visceral adipocytes produce more adiponectin than adipocytes isolated from subcutaneous fat is rather puzzling.

In intervention studies, circulating adiponectin levels increased after weight loss in humans. Diet, gastric bypass surgery, orlistat, or selective CBI-receptor blockade with rimonabant significantly increased adiponectin levels in parallel to reduced body weight (27). Thiazolidinediones increased adiponectin expression and circulating levels in rodents, nondiabetic subjects, and patients with type 2 diabetes (28). Exercise without significant weight loss did not affect circulating adiponectin, but improved insulin resistance, suggesting different pathways for the insulin-sensitive mechanism of exercise other than adipokine modulation (28).

Genetic polymorphisms, sex, and dietary factors, such as soy protein, fish oils, linoleic acid, and carbohydrate-rich diets also influence circulating adiponectin (28).

\section{Adiponectin and insulin sensitivity}

Circulating adiponectin levels are positively correlated with insulin sensitivity evaluated by using different insulin sensitivity techniques (28). Adiponectin gene expression and circulating adiponectin levels are lower in patients with type 2 diabetes than in nondiabetic individuals (28). In a prospective study of 3,599 nondiabetic men followed up for 5 years, low adiponectin was associated with increased risk of type 2 diabetes, even after adjustment for traditional risk factors, and the same results were found in a cohort study representing the $\sim 9$-year experience of the 10,275 middle-aged U.S. African American and Caucasian participants of the Atherosclerosis Risk in Communities Study and in the Hoorn Study $(29,30)$

Several single-nucleotide polymorphisms and mutations in the adiponectin gene have been reported to be linked to type 2 diabetes and hypoadiponectinemia in different ethnic groups (25). 


\section{Animal models}

Adiponectin-deficient mice develop insulin resistance, glucose intolerance, increased lipid deposition in muscle, hyperlipidemia, and increased susceptibility to atherosclerosis (28). Adiponectin administration led to decreased circulating glucose levels in both normal mice and mouse models of diabetes (25). Mice overexpressing adiponectin showed normalized glucose and partial amelioration of insulin resistance and diabetes and a reduction in macrophage infiltration in adipose tissue and systemic inflammation (31).

Adiponectin plays a special role in insulin sensitivity in the liver. Adiponectin lowers hepatic gluconeogenesis in mice (25), enhances the effects of insulin to decrease glucose production by isolated hepatocytes, and decreases hepatic triglyceride deposition (25). Moreover, adiponectin can also reduce ectopic fat deposition in muscle via increases of fat oxidation (28), improving insulin signal transduction. Accordingly, low adiponectin concentrations in obese adolescent subjects are associated with increased intramyocellular lipid deposition and impaired insulin action (32).

\section{Molecular mechanisms}

Adiponectin exerts its effects on energy homeostasis, and glucose and lipid metabolism through phosphorylation and activation of adenosine monophosphateactivated protein kinase (AMPK) (25). The AMPK activation stimulates phosphorylation of acetyl CoA carboxylase, fatty acid oxidation and glucose uptake in myocytes, and reduces enzymes involved in gluconeogenesis in liver, leading to reduction of glucose levels (25).

Adiponectin also increased the expression levels of PPAR- $\alpha$ in vivo, increasing fatty acid combustion and energy consumption, which led to decreased triglyceride content in the liver and skeletal muscle, and thus increased insulin sensitivity. Moreover, PPAR- $\alpha$ activation prevented inflammation in adipose tissue and enhanced the action of adiponectin by increasing both adiponectin and adiponectin receptors, which can result in the amelioration of obesity-induced insulin resistance $(28,31)$.

\section{Adiponectin and atherosclerosis}

Studies in animal models and humans have shown associations among adiponectin, endothelial function, and car- diovascular disease (33). Adiponectin has been reported to have direct antiatherosclerotic effects by suppressing the expression of intracellular adhesion molecule-1, E-selectin, and vascular cellular adhesion molecule- 1 , as well as by reducing the effects of TNF-mediated proinflammatory changes on endothelial cells. Adiponectin inhibits the expression of the macrophage-associated scavenger receptor class A-1, decreasing foam cell formation (25). Globular adiponectin also inhibits oxidized LDL-mediated endothelial proliferation and formation of reactive oxygen species integral to vascular damage. Adiponectin knockout mice developed severe vascular alterations, including reduced vasodilation in response to acetylcholine, neointimal thickening, and increased proliferation of smooth muscle cells in arteries after injury, while overexpression of adiponectin in mice resulted in marked reduction of atherosclerotic lesion formation (25).

In addition to the direct protective effects of adiponectin on vascular endothelium, the associations between low adiponectin and atherosclerosis are in part due to its relationship with other cardiovascular risk factors, such as insulin resistance, type 2 diabetes, intraabdominal body fat distribution, hypertension, small dense LDL, triglycerides, and HDL levels (34).

Although the anti-atherosclerotic effects of adiponectin seem to be strong, the association between adiponectin and cardiovascular disease risk in different prospective and case-control studies is comparatively moderate or not significant, especially after adjusting for HDL cholesterol levels (35).

\section{Recent controversies}

Despite the well-known insulinsensitizing and anti-atherosclerotic effects of adiponectin, recent findings disclosed unsuspected relationships. In a cohort of male patients with high cardiovascular risk, plasma adiponectin was independently predictive of the subsequent risk of death and myocardial infarction (36). High adiponectin levels were also found as predictors of mortality in subjects with chronic heart failure (37). Simvastatin treatment improved endotheliumdependent vasodilation but reduced adiponectin levels (38). The contradictory findings can be explained in part by the stratification of different cardiovascular risk factors in the populations studied. As previously suggested, increased secretion of adiponectin may reflect an insufficient response to avoid endothelial damage in subjects with high cardiovascular risk. However, in other high-risk populations, this hypothesis could not be confirmed (36).

Despite the well-documented negative association between adiponectin and several inflammatory factors, adiponectin was found to be actually increased in chronic inflammation associated with autoimmune diseases, such as type 1 diabetes, systemic lupus erythematosus, rheumatoid arthritis, and inflammatory bowel disease, suggesting that adiponectin increases in chronic inflammation not associated with obesity. It is possible that adiponectin could have a protective role in the inflammation related to adipose tissue loss during starvation and fasting, but not in inflammation unassociated with obesity.

CONCLUSIONS - Genetic predisposition, overt and inappropriate nutrition, and different environmental influences lead to obesity or hyperplasia of adipose tissue and to infiltration by proinflammatory macrophages. Increased adipose tissue produces and secretes a variety of biologically active mediators (adipocytokines) that are thought to contribute to the development of insulin resistance, type 2 diabetes, and cardiovascular disease. Inflammatory factors, such as IL-6, TNF- $\alpha$, and RBP4, can induce insulin resistance by antagonizing insulin action at peripheral tissues, especially the liver and skeletal muscle. Several other adipokines produced by the adipocytes, including adiponectin (and possibly LCN2), demonstrated insulin-sensitizing activity and cardiovascular protection.

Despite the well-characterized protective effects of adiponectin on insulin resistance and atherosclerosis, the divergent findings concerning the role of adiponectin on chronic inflammation not associated with obesity should be confirmed. The direct anti-atherosclerotic effects of adiponectin without the influence of insulin resistance and dyslipidemia should also be clarified. More data on the role of LCN2 on inflammation in humans are needed. The in vivo balances of different pro- and anti-inflammatory cytokines and their diverging interrelationships need to be explored in depth to understand the different biological pathways that are involved (Fig. 1). 
Acknowledgments - No potential conflicts of interest relevant to this article were reported.

\section{References}

1. Fernández-Real JM, Ricart W. Insulin resistance and chronic cardiovascular inflammatory syndrome. Endocr Rev 2003; 24:278-301

2. Skurk T, Alberti-Huber C, Herder C, Hauner H. Relationship between adipocyte size and adipokine expression and secretion. J Clin Endocrinol Metab 2007; 92:1023-1033

3. Fernández-Real JM, Pickup JC. Innate immunity, insulin resistance and type 2 diabetes. Trends Endocrinol Metab 2008; 19 : $10-16$

4. Kjeldsen L, Bainton DF, Sengelov H, Borregaard $\mathrm{N}$. Identification of neutrophil gelatinase-associated lipocalin as a novel matrix protein of specific granules in human neutrophils. Blood 1994;83:799_ 807

5. Wang Y, Lam KS, Kraegen EW, Sweeney G, Zhang J, Tso AW, Chow WS, Wat NM, $\mathrm{Xu}$ JY, Hoo RL, Xu A. Lipocalin-2 is an inflammatory marker closely associated with obesity, insulin resistance, and hyperglycemia in humans. Clin Chem 2007; 53:34-41

6. Flo TH, Smith KD, Sato S, Rodriguez DJ, Holmes MA, Strong RK, Akira S, Aderem A. Lipocalin 2 mediates an innate immune response to bacterial infection by sequestrating iron. Nature 2004:432:917-921

7. Shen F, Hu Z, Goswami J, Gaffen SL. Identification of common transcriptional regulatory elements in interleukin-17 target genes. J Biol Chem 2006;281:2413824148

8. Yan QW, Yang Q, Mody N, Graham TE, Hsu CH, Xu Z, Houstis NE, Kahn BB, Rosen ED. The adipokine lipocalin 2 is regulated by obesity and promotes insulin resistance. Diabetes 2007;56:2533-2540

9. Choi KM, Lee JS, Kim EJ, Baik SH, Seo HS, Choi DS, Oh DJ, Park CG. Implication of lipocalin-2 and visfatin levels in patients with coronary heart disease. Eur J Endocrinol 2008;158:203-207

10. Zhang J, Wu Y, Zhang Y, Leroith D, Bernlohr DA, Chen X. The role of lipocalin 2 in the regulation of inflammation in adipocytes and macrophages. Mol Endocrinol 2008:22:1416-1426

11. Yang Q, Graham TE, Mody N, Preitner F, Peroni OD, Zabolotny JM, Kotani K, Quadro L, Kahn BB. Serum retinol binding protein 4 contributes to insulin resistance in obesity and type 2 diabetes. Nature 2005:436:356-362

12. Kovacs P, Geyer M, Berndt J, Klöting N, Graham TE, Böttcher Y, Enigk B, Tönjes A, Schleinitz D, Schön MR, Kahn BB, Blüher M, Stumvoll M. Effects of genetic vari- ation in the human retinol binding protein-4 gene (RBP4) on insulin resistance and fat depot-specific mRNA expression. Diabetes 2007;56:3095-3100

13. Graham TE, Yang Q, Blüher M, Hammarstedt A, Ciaraldi TP, Henry RR, Wason CJ, Oberbach A, Jansson PA, Smith U, Kahn BB. Retinol-binding protein 4 and insulin resistance in lean, obese, and diabetic subjects. N Engl J Med 2006;354: 2552-2563

14. Stefan N, Hennige AM, Staiger $H$, Machann J, Schick F, Schleicher E, Fritsche A, Häring HU. High circulating retinol-binding protein 4 is associated with elevated liver fat but not with total, subcutaneous, visceral, or intramyocellular fat in humans. Diabetes Care 2007:30: $1173-1178$

15. Promintzer M, Krebs M, Todoric J, Luger A, Bischof MG, Nowotny P, Wagner O, Esterbauer $\mathrm{H}$, Anderwald $\mathrm{C}$. Insulin resistance is unrelated to circulating retinol binding protein and protein C inhibitor. J Clin Endocrinol Metab 2007;92:4306-4312

16. Broch M, Vendrell J, Ricart W, Richart C, Fernández-Real JM. Circulating retinolbinding protein- 4 , insulin sensitivity, insulin secretion, and insulin disposition index in obese and nonobese subjects. Diabetes Care 2007;30:1802-1806

17. Gavi S, Stuart LM, Kelly P, Melendez MM, Mynarcik DC, Gelato MC, McNurlan MA. Retinol-binding protein 4 is associated with insulin resistance and body fat distribution in non-obese subjects without type 2 diabetes. J Clin Endocrinol Meta 2007:92:1886-1890

18. Lee JW, Im JA, Lee HR, Shim JY, Youn BS, Lee DC. Visceral adiposity is associated with serum retinol binding protein-4 levels in healthy women. Obesity (Silver Spring) 2007;15:2225-2232

19. Klöting N, Graham TE, Berndt J, Kralisch S, Kovacs P, Wason CJ, Fasshauer M, Schön MR, Stumvoll M, Blüher M, Kahn BB. Serum retinol-binding protein is more highly expressed in visceral than in subcutaneous adipose tissue and is a marker of intra-abdominal fat mass. Cell Metab 2007;6:79-87

20. Craig RL, Chu WS, Elbein SC. Retinol binding protein 4 as a candidate gene for type 2 diabetes and prediabetic intermediate traits. Mol Genet Metab 2007; 90:338-344

21. Ost A, Danielsson A, Lidén M, Eriksson U, Nystrom FH, Strålfors P. Retinol-binding protein-4 attenuates insulin-induced phosphorylation of IRS1 and ERK1/2 in primary human adipocytes. FASEB J 2007;21:3696-3704

22. Cho YM, Youn BS, Lee H, Lee N, Min SS, Kwak SH, Lee HK, Park KS. Plasma retinol-binding protein- 4 concentrations are elevated in human subjects with impaired glucose tolerance and type 2 diabetes. Diabetes Care 2006;29:2457-2461
23. Fernandez-Real JM, Moreno JM, Ricart W. Circulating RBP4 concentration might reflect insulin resistance-associated iron overload. Diabetes 2008;57:1918-1925

24. Haider DG, Schindler K, Prager G, Bohdjalian A, Luger A, Wolzt M, Ludvik B. Serum retinol-binding protein 4 is reduced after weight loss in morbidly obese subjects. J Clin Endocrinol Metab 2007;92: 1168-1171

25. Kadowaki T, Yamauchi T. Adiponectin and adiponectin receptors. Endocr Rev 2005:26:439-451

26. Taksali SE, Caprio S, Dziura J, Dufour S, Calí AM, Goodman TR, Papademetris X, Burgert TS, Pierpont BM, Savoye M, Shaw M, Seyal AA, Weiss R. High visceral and low abdominal subcutaneous fat stores in the obese adolescent: a determinant of an adverse metabolic phenotype. Diabetes 2008; 57:367-371

27. Després JP, Golay A, Sjöström L. Rimonabant in Obesity-Lipids Study Group: Effects of rimonabant on metabolic risk factors in overweight patients with dyslipidemia. N Engl J Med 2005;353:21212134

28. Kadowaki T, Yamauchi T, Kubota N, Hara K, Ueki K, Tobe K. Adiponectin and adiponectin receptors in insulin resistance, diabetes, and the metabolic syndrome. J Clin Invest 2006;116:1784-1792

29. Duncan BB, Schmidt MI, Pankow JS, Bang $\mathrm{H}$, Couper D, Ballantyne CM, Hoogeveen RC, Heiss G. Adiponectin and the development of type 2 diabetes: the Atherosclerosis Risk in Communities Study. Diabetes 2004:53:2473-2478

30. Snijder MB, Heine RJ, Seidell JC, Bouter LM, Stehouwer CD, Nijpels G, Funahashi T, Matsuzawa Y, Shimomura I, Dekker JM. Associations of adiponectin levels with incident impaired glucose metabolism and type 2 diabetes in older men and women: the Hoorn study. Diabetes Care 2006;29:2498-2503

31. Kim JY, van de Wall E, Laplante M, Azzara A, Trujillo ME, Hofmann SM, Schraw T, Durand JL, Li H, Li G, Jelicks LA, Mehler MF, Hui DY, Deshaies Y, Shulman GI, Schwartz GJ, Scherer PE. Obesity-associated improvements in metabolic profile through expansion of adipose tissue. J Clin Invest 2007;117:2621-2637

32. Weiss R, Dufour S, Groszmann A, Petersen K, Dziura J, Taksali SE, Shulman G, Caprio S. Low adiponectin levels in adolescent obesity: a marker of increased intramyocellular lipid accumulation. J Clin Endocrinol Metab 2003;88:2014-2018

33. Kumada M, Kihara S, Sumitsuji S, Kawamoto T, Matsumoto S, Ouchi N, Arita Y, Okamoto Y, Shimomura I, Hiraoka H, Nakamura T, Funahashi T, Matsuzawa Y, Osaka CAD Study Group. Association of hypoadiponectinemia with coronary artery disease in men. Arterioscler Thromb Vasc Biol 2003;23:85-89 


\section{Esteve, Ricart, and Fernández-Real}

34. Kazumi T, Kawaguchi A, Sakai K, Hirano $\mathrm{T}$, Yoshino G. Young men with high-normal blood pressure have lower serum adiponectin, smaller LDL size, and higher elevated heart rate than those with optimal blood pressure. Diabetes Care 2002; 25:971-976

35. Sattar N, Wannamethee G, Sarwar N, Tchernova J, Cherry L, Wallace AM, Danesh J, Whincup PH. Adiponectin and coronary heart disease: a prospective study and meta-analysis. Circulation 2006;114:623-629

36. Cavusoglu E, Ruwende C, Chopra V, Yanamadala S, Eng C, Clark LT, Pinsky DJ, Marmur JD. Adiponectin is an independent predictor of all-cause mortality, cardiac mortality, and myocardial infarction in patients presenting with chest pain. Eur Heart J 2006;27:23002309

37. Kistorp C, Faber J, Galatius S, Gustafsson
F, Frystyk J, Flyvbjerg A, Hildebrandt P. Plasma adiponectin, body mass index, and mortality in patients with chronic heart failure. Circulation 2005;112:17561762

38. Koh KK, Quon MJ, Han SH, Lee Y, Ahn JY, Kim SJ, Koh Y, Shin EK. Simvastatin improves flow-mediated dilation but reduces adiponectin levels and insulin sensitivity in hypercholesterolemic patients. Diabetes Care 2008;31:776-782 